\title{
Tertiary hypothyroidism in a dog
}

Robert E. Shiel, Els Acke, Antonella Puggioni, Joseph P. Cassidy \& Carmel T. Mooney

School of Agriculture, Food Science and Veterinary Medicine, University College Dublin, Belfield, Dublin 4, Ireland

\section{Corresponding author:}

Robert E. Shiel, School of Agriculture, Food Science and Veterinary Medicine, University College Dublin, Belfield, Dublin 4, Ireland

Email: robert.shiel@ucd.ie

Tel: $\quad 017166015$

Fax: $\quad 017166023$

A nine-year-old male entire Labrador was diagnosed with pituitary dependent hyperadrenocorticism. Following seven months of successful mitotane therapy, the dog presented with marked weight gain, seborrhoea and alopecia. Routine clinicopathological analyses revealed marked hypercholesterolaemia. Serum total and free thyroxine (T4) concentrations were below their respective reference ranges. Serum thyroid stimulating hormone (cTSH) concentration was within reference range. TSH and thyrotropin releasing hormone $(\mathrm{TRH})$ response tests revealed adequate stimulation of total T4 in both, and CTSH in the latter test. Magnetic resonance imaging revealed a mass arising from the pituitary fossa, with suprasellar extension. A diagnosis of tertiary hypothyroidism was made. Following four weeks of levothyroxine therapy, circulating cholesterol concentration had declined, weight loss had ensued and dermatological abnormalities had improved. Euthanasia was performed four months later due to the development of neurological signs. A highly infiltrative pituitary adenoma, with effacement of the overlying hypothalamus was identified on post mortem examination. Tertiary hypothyroidism has not been previously reported in dogs.

Key words: hypothyroidism, hypothalamus, tertiary, hyperadrenocorticism, dogs

\section{Introduction}

Hypothyroidism is a common endocrine disorder of dogs, with an estimated prevalence of $0.2 \%$ (Panciera, 1994). Central hypothyroidism reportedly accounts for less than $5 \%$ of these cases (Feldman and Nelson, 2004), and is theoretically caused by decreased thyroidal T4 and $\mathrm{T} 3$ production due to a reduction in pituitary thyroid stimulating hormone (cTSH) (secondary hypothyroidism) or hypothalamic thyrotropin releasing hormone (TRH) (tertiary hypothyroidism) secretion.

Central hypothyroidism is most commonly associated with congenital disorders affecting the pituitary gland (Eigenmann, 1981; Greco et al., 1991; Mooney and Anderson, 1993; Hamann et al., 1999; Kooistra et al., 2000). Central hypothyroidism has also been reported in dogs in association with neoplasia (Neer and Reavis, 1983; Barr, 1985; Hare, 1993), however, a definitive diagnosis was not achieved in all cases, and attempts were not made to differentiate between secondary and tertiary disease. This case report is the first confirmed case of canine tertiary hypothyroidism.

\section{Case history}

A nine-year-old entire male Labrador, weighing $48.2 \mathrm{~kg}$, was examined at the University Veterinary Hospital (UVH), University College Dublin for the investigation of polyuria, polydipsia and polyphagia of several months' duration. Coat quality was poor, with mild generalised seborrhoea, patchy alopecia and thinning with loss of elasticity of the ventral abdominal skin. Moderate abdominal distension was present.

Table 1: Routine clinicopathological findings

\begin{tabular}{|c|c|c|c|c|c|}
\hline Parameter & $\begin{array}{l}\text { Initial } \\
\text { presentation }\end{array}$ & $\begin{array}{l}\text { Seven months later (pre- } \\
\text { levothyroxine treatment) }\end{array}$ & $\begin{array}{l}\text { Ten months later } \\
\text { (one month following } \\
\text { commencement of } \\
\text { levothyroxine) }\end{array}$ & $\begin{array}{l}14 \text { months later } \\
\text { (at time of } \\
\text { euthanasia) }\end{array}$ & Reference range \\
\hline Alkaline phosphatase (iu/L) & 1065 & 360 & 338 & 185 & $5-50$ \\
\hline Alanine aminotransferase (iu/L) & 255 & 31 & 23 & 12 & $5-20$ \\
\hline Creatine kinase (iu/L) & 73 & 59 & 59 & 21 & $0-50$ \\
\hline Cholesterol (mmol/L) & 13.2 & 15 & 6.4 & 6.7 & $3.2-6.5$ \\
\hline
\end{tabular}


Table 2: Adrenal function test results

\begin{tabular}{|c|c|c|c|}
\hline Test & & Result & Reference range \\
\hline \multicolumn{4}{|l|}{ Initial diagnosis } \\
\hline \multirow[t]{2}{*}{ ACTH stimulation test } & Pre-ACTH cortisol & $163 \mathrm{nmol} / \mathrm{L}$ & \\
\hline & Post-ACTH cortisol & $968 \mathrm{nmol} / \mathrm{L}$ & $<450 \mathrm{nmol} / \mathrm{L}$ \\
\hline \multirow[t]{3}{*}{ Low dose dexamethasone suppression test } & Basal sample & $229 \mathrm{nmol} / \mathrm{L}$ & \\
\hline & 3 hour sample & $155 \mathrm{nmol} / \mathrm{L}$ & \\
\hline & 8 hour sample & $331 \mathrm{nmol} / \mathrm{L}$ & $<30 \mathrm{nmol} / \mathrm{L}$ \\
\hline Endogenous ACTH & & $119 \mathrm{pg} / \mathrm{mL}$ & $20-80 \mathrm{pg} / \mathrm{mL}$ \\
\hline \multicolumn{4}{|l|}{ Monitoring therapy } \\
\hline \multirow[t]{2}{*}{ ACTH stimulation test (after 5 days induction) } & Pre-ACTH cortisol & $34.3 \mathrm{nmol} / \mathrm{L}$ & \\
\hline & Post-ACTH cortisol & $58.2 \mathrm{nmol} / \mathrm{L}$ & $<120 \mathrm{nmol} / \mathrm{L}$ \\
\hline \multirow[t]{2}{*}{ ACTH stimulation test (1 month) } & Pre-ACTH cortisol & $<27.59 \mathrm{nmol} / \mathrm{L}$ & \\
\hline & Post-ACTH cortisol & $67.7 \mathrm{nmol} / \mathrm{L}$ & $<120 \mathrm{nmol} / \mathrm{L}$ \\
\hline \multirow[t]{2}{*}{ ACTH stimulation test (3 months) } & Pre-ACTH cortisol & $41.5 \mathrm{nmol} / \mathrm{L}$ & \\
\hline & Post-ACTH cortisol & $96.4 \mathrm{nmol} / \mathrm{L}$ & $<120 \mathrm{nmol} / \mathrm{L}$ \\
\hline \multirow[t]{2}{*}{ ACTH stimulation test ( 7 months) } & Pre-ACTH cortisol & $53.5 \mathrm{nmol} / \mathrm{L}$ & \\
\hline & Post-ACTH cortisol & $102 \mathrm{nmol} / \mathrm{L}$ & $<120 \mathrm{nmol} / \mathrm{L}$ \\
\hline
\end{tabular}

ACTH = Adrenocorticotropic hormone

Routine clinicopathological analyses revealed lymphopenia and eosinopenia with elevated alkaline phosphatase (AP), alanine aminotransferase (ALT), creatine kinase (CK) and cholesterol concentrations (Table 1). Urinalysis revealed hyposthenuria (specific gravity 1.005). Results of adrenocorticotropic hormone $(\mathrm{ACTH})$ response and low dose dexamethasone suppression tests were supportive of hyperadrenocorticism (Table 2). Two similarly sized adrenal glands [caudal pole width of $12.9 \mathrm{~mm}$ (left) and $10.7 \mathrm{~mm}$ (right)] identified ultrasonographically together with elevated plasma endogenous ACTH concentration confirmed pituitary dependent hyperadrenocorticism (Table 2).

Treatment with mitotane at $50 \mathrm{mg} / \mathrm{kg}$ p.o. once daily resulted in adequate control after five days of treatment (as determined by repeat ACTH response testing and reduced water intake), and once weekly maintenance therapy at the above dose was commenced. Prednisolone $(0.2 \mathrm{mg} / \mathrm{kg}$ p.o. once daily) was also prescribed, to be given only if clinical signs of hypocortisolaemia developed. ACTH stimulation testing confirmed adequate control one and three months after commencing maintenance therapy (Table 2).

The dog was re-examined at the UVH seven months following the initial diagnosis of hyperadrenocorticism. There had been significant weight gain (weight $55.7 \mathrm{~kg}$ ). Lethargy and dullness had also developed and, despite initial improvement, the coat quality had deteriorated with extensive seborrhoea and alopecia. Polyuria, polydipsia and polyphagia had not been observed. Prednisolone, at the above replacement dose, had been administered by the owner over one week, but was discontinued when no improvement was noted.

Routine clinicopathological tests were repeated and amarked hypercholesterolaemia was detected (Table 1). An ACTH stimulation test showed adequate control of hyperadrenocorticism (Table 2). Basal serum total and free thyroxine (T4) values were below their respective reference ranges (Table 3). Serum cTSH concentration was within the lower end of the reference range (Table 3). A TSH stimulation test was performed using $75 \mu \mathrm{g}$ of intravenous recombinant human TSH (Thyrogen, Genzyme corporation) (Sauvé and Paradis, 2000; Roover et al., 2003) and revealed an adequate rise in concentration of total T4 after six hours (Table 3). A TRH response test was

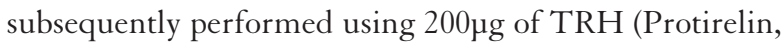
Cambridge Labs, Cambridge, UK) (Scott-Moncrieff and Nelson, 1998) and revealed a substantial elevation in cTSH concentration after 30 minutes and an adequate increase in total T4 after four hours (Table 3). Magnetic resonance

Table 3: Thyroid function test results

\begin{tabular}{|l|l|l|}
\hline PARAMETER & Result & Reference range \\
\hline Basal total T4 $(\mathrm{nmol} / \mathrm{L})$ & $<6.435$ & $150-50$ \\
\hline Basal cTSH $(\mathrm{ng} / \mathrm{mL})$ & 0.1 & $<0.68$ \\
\hline Free T4 $(\mathrm{pmol} / \mathrm{L})$ & 4.0 & $6.6-40$ \\
\hline TSH response test & & See below \\
\hline Basal total T4 & 9.9 & \\
\hline 4 hour total T4 & 29.3 & See below \\
\hline TRH response test & & \\
\hline Basal total T4 & 12.1 & \\
\hline Basal cTSH & 0.07 & \\
\hline $\begin{array}{l}\text { 30 minute cTSH } \\
\text { 4 hour total T4 }\end{array}$ & 0.56 & \\
\hline Monitoring treatment & 23.9 & $>35 \mathrm{nmol} / \mathrm{L}$ \\
\hline 1 month total T4 & 51.2 & \\
\hline 1 month cTSH & $<0.03$ & \\
\hline
\end{tabular}

TSH response test

A post TSH total T4 concentration above $25 \mathrm{nmol} / \mathrm{L}$, and a greater than 1.5 fold increase over basal concentrations, precludes primary hypothyroidism (Dixon and Mooney, 1999).

TRH response test

A post TRH total T4 concentration greater than $6 \mathrm{nmol} / \mathrm{L}$ over the basal

concentration, and a greater than 1.5 fold increase over the basal concentration, makes both primary and secondary hypothyroidism unlikely (Panciera, 1998). 


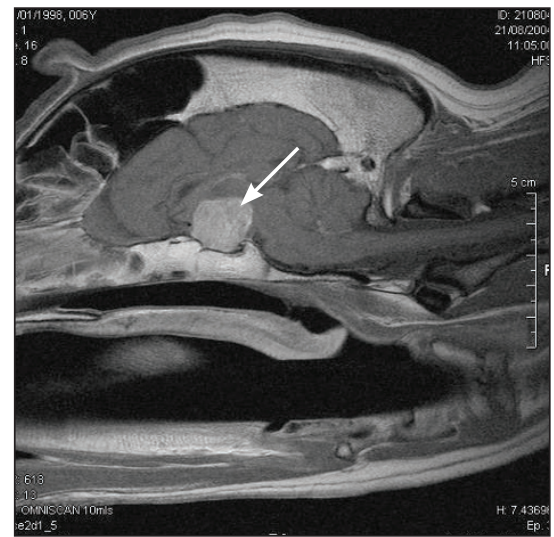

Figure 1:

Sagittal T1 weighted post contrast image of the brain, showing a homogeneously enhancing, irregularly marginated mass of $2 \mathrm{~cm}$ in diameter in the pituitary fossa (indicated with arrow). The mass extends dorsally and rostrally.

imaging (MRI) revealed a roughly bilobed, $2 \times 2 \times 3 \mathrm{~cm}$ mass arising from the pituitary fossa, showing suprasellar extension dorsally and rostrally, with a marked mass effect on neighbouring structures (Figures $\mathbf{1}$ and 2).

A diagnosis of tertiary hypothyroidism was made, and treatment with levothyroxine commenced $(0.8 \mathrm{mg}$ p.o. once daily). When the dog was re-examined four weeks later, seborrhoea was less marked and hair regrowth had commenced. The owner reported improved demeanour and exercise tolerance and body weight had reduced to $52.5 \mathrm{~kg}$. Cholesterol had reduced to within reference range (Table $\mathbf{1}$ ) and serum total $\mathrm{T} 4$ confirmed adequate replacement therapy (Table 3) (Dixon et al., 2002).

Two months following commencement of treatment of hypothyroidism, the dermatological changes had further improved but dullness, depression, head pressing and mild ataxia had developed. Neurological examination was otherwise unremarkable. Prednisolone was commenced at a high dose $(2 \mathrm{mg} / \mathrm{kg} /$ day $)$, but resulted in only short term, partial improvement. Euthanasia was performed two months later due to progression of the neurological signs.

Post mortem examination revealed the presence of a highly infiltrative pituitary adenoma with effacement of the overlying hypothalamus (Figure 3). Pituitary histopathology revealed a dense aggregate of pleomorphic cells of cuboidal to polygonal outline with eosinophilic cytoplasm and ovoid, frequently hyperchromatic nuclei. Tumour cells were noted pallisading around blood vessels. Rare attempts at acinar formation were observed. Multinucleated cells and karyomegaly were features and one mitotic figure per high power field was counted (Figure 4). A small amount of compressed pituitary tissue was identified grossly but was not apparent on histopathology sections. The thyroid gland was grossly reduced in size. Histopathologically, there was a large percentage of small diameter follicles containing clumped or little colloid with no evidence of inflammatory cell infiltration. The corticomedullary junction of both adrenal glands was irregular with a cortical-medullary ratio of $1: 1$. Histopathology revealed cortical atrophy with hyperplastic nodules and foci of mineralisation within the cortex.

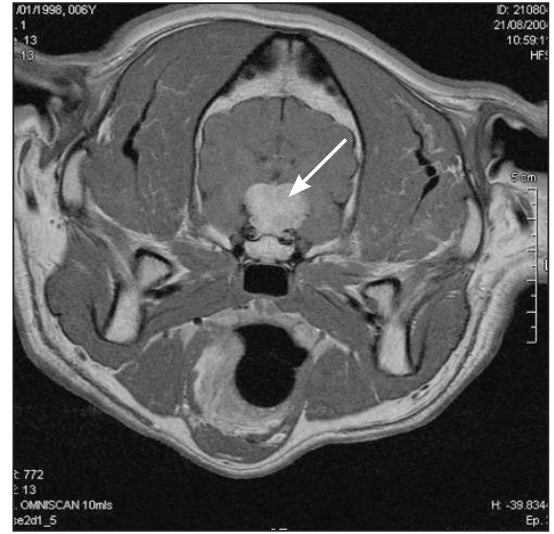

Figure 2:

Transverse T1 weighted post contrast image of the brain. The hyperintense mass in the 'sella turcica' appears bilobed and mildly asymmetric, protruding slightly towards the left cerebral hemisphere (indicated with arrow)

\section{Discussion}

Central hypothyroidism is rare in humans, estimated to occur in $0.005 \%$ of the general population (Martino and Pinchero, 2005). Most cases are associated with congenital defects, however various acquired structural and functional disorders have also been described. Congenital defects also appear to be the most common cause of canine central hypothyroidism. Spontaneous central hypothyroidism has rarely been reliably diagnosed in adult dogs, and differentiation into secondary and tertiary disease was not attempted in reported cases.

Lethargy, dullness, weight gain, seborrhoea and alopecia were present in this case; features consistent with a diagnosis of hypothyroidism (Dixon et al., 1999). Lethargy and dullness may be associated with pituitary macrotumours, but this was thought unlikely due to lack of other neurological signs and complete resolution of these signs following T4 replacement therapy. The improved demeanour and dermatological features, increased exercise tolerance and weight loss following treatment are further supportive of hypothyroidism. Some dermatological abnormalities had not fully resolved after initiation of treatment, but it can take up to six months before full improvement is noted (Dixon et al., 2002; Dixon, 2004). The neurological signs observed terminally in this case were more likely due to tumour expansion rather than hypothyroidism, as replacement therapy was adequate, and the other clinical signs of hypothyroidism were improving at the time of development.

The elevated cholesterol and creatine kinase concentrations were consistent with hypothyroidism (Dixon et al., 1999). Other causes of marked hypercholesterolaemia, including excessive endogenous (uncontrolled hyperadrenocorticism) or exogenous glucocorticoids, diabetes mellitus, cholestasis, nephrotic syndrome and primary hyperlipidaemia and hypercholesterolaemia, were excluded during the investigation, or would not have improved with levothyroxine treatment alone. Hyperadrenocorticism had been adequately controlled for several months at the time of investigation of hypothyroidism. Prednisolone had been prescribed, but replacement dosages are unlikely to induce 


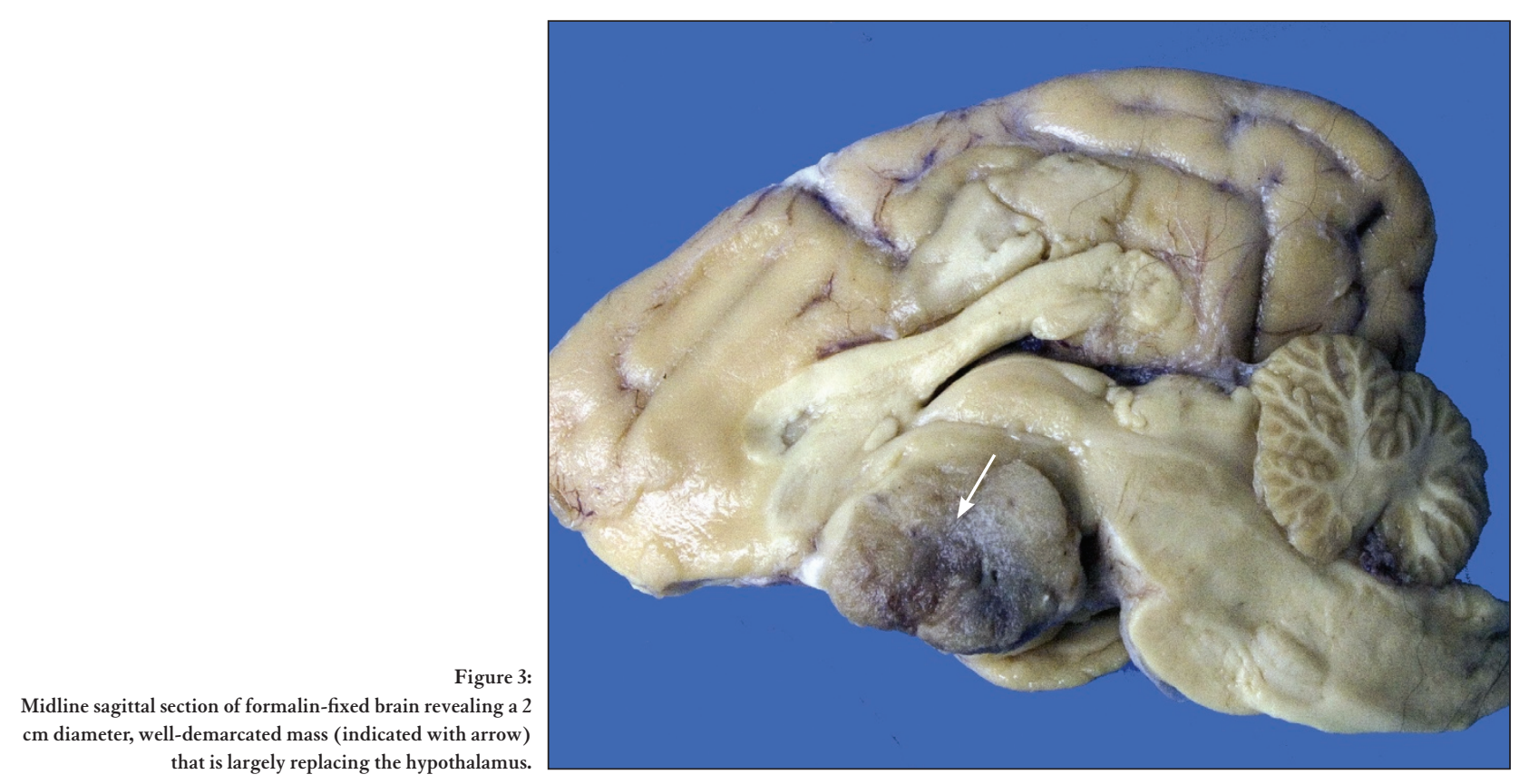

such marked hypercholesterolaemia and prednisolone had been discontinued three weeks preceding thyroid function testing (Dillon et al., 1980).

Low serum total and free T4 concentrations were present in this dog. Basal serum total and free T4 concentrations are invariably low in hypothyroidism, but both can also be suppressed by various non-thyroidal factors, including drug therapy and non-thyroidal illness. Prednisolone had been administered at replacement doses to this dog. Although immunosuppressive doses of prednisolone are associated with reduced total T4 concentrations, anti-inflammatory doses administered over one month do not have an effect on either total or free T4 concentrations (Torres et al., 1991; Moore et al., 1993). Non-thyroidal illness is commonly associated with reduced total $\mathrm{T} 4$ concentrations, but free $\mathrm{T} 4$ concentrations are typically only suppressed by severe illness (Kantrowitz et al., 2001). No signs of severe non-thyroidal illness were present in this case and were also unlikely given the marked improvement with levothyroxine therapy alone. Only clinical signs consistent with hypothyroidism were exhibited. Hyperadrenocorticism is commonly associated with reduced free and total T4 concentrations (Nelson et al., 1991; Ferguson and Peterson, 1992). Although this disease was originally present, it was adequately controlled at the time of sampling (determined by ACTH response test and clinical signs) when both total and free T4 concentrations are expected to be within their respective reference ranges (Peterson et al., 1984). Therefore, these results are supportive of a diagnosis of hypothyroidism, but they do not differentiate between primary and central disease.

The serum cTSH concentration was within reference range. Such a result would be expected in central hypothyroidism, and may occur in $20-30 \%$ of primary hypothyroidism cases consequent to pituitary exhaustion or production of cTSH isoforms not detected by the assay (Dixon, 2004). Concentrations of cTSH can be suppressed by concurrent drug administration or non-thyroidal illness, and it is possible that prednisolone lowered concentrations in this case. However, prednisolone was given for only one week at a replacement dose, and treatment with 30 $\mathrm{mg}$ of prednisone for one week in human patients did not influence basal TSH concentration (Brabant et al., 1989). In humans, low TSH concentrations are commonly seen in patients with central hypothyroidism, but the current canine assay cannot distinguish between low and normal concentrations and, as a consequence, the presence of a reference range cTSH value can be consistent with central hypothyroidism.

The post TSH total T4 concentration was above $25 \mathrm{nmol} / \mathrm{L}$, and demonstrated a greater than 1.5 fold increase over basal concentrations, precluding primary hypothyroidism (Dixon and Mooney, 1999). This result could occur in central hypothyroidism or euthyroidism. Reduced T4 responses to TSH administration have been reported in animals with congenital and acquired secondary hypothyroidism (Greco et al., 1991; Mellanby et al., 2005), but this response is dependent on the duration of the disease and the severity of thyroid gland atrophy. As a consequence, normal stimulation following either single or repeated TSH administrations is possible with central hypothyroidism (Feldman and Nelson, 1987).

The post TRH total T4 concentration demonstrated a greater than 1.5 fold increase, and greater than $6 \mathrm{nmol} / \mathrm{L}$ increase over the basal concentration, making both primary and secondary hypothyroidism unlikely (Panciera, 1998). The cTSH response to TRH administration was similar to that described in euthyroid dogs, also making secondary 


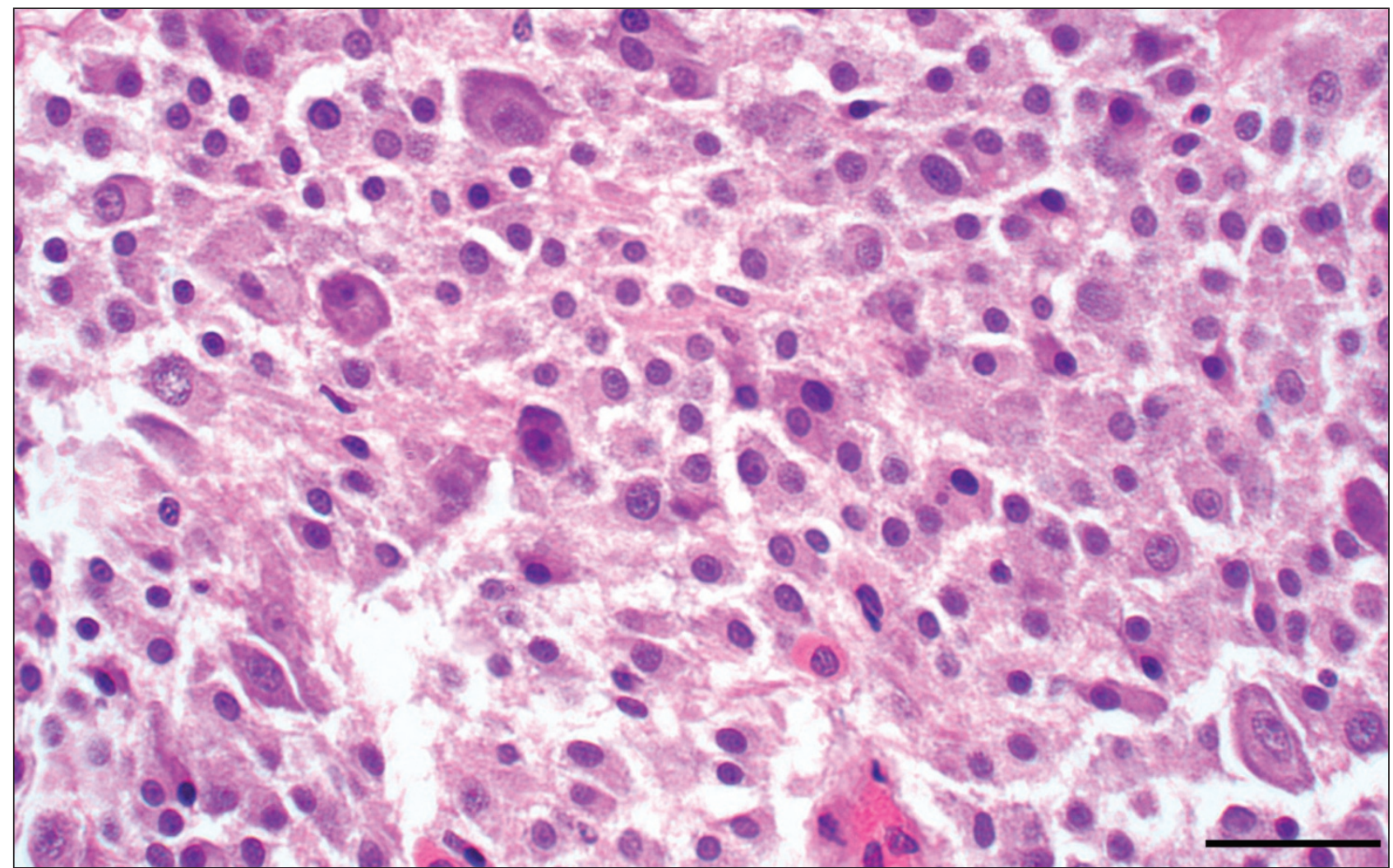

Figure 4: Photomicrograph of neoplasm reveals a dense aggregate of pleomorphic cells of cuboidal to polygonal outline with eosinophilic cytoplasm and ovoid, frequently hyperchromatic, nuclei. Tumour cells are noted pallisading around blood vessels. Rare attempts at acinar formation are observed. Multinucleated cells and karyomegaly are features and one mitotic figure per high power field is counted. (Haematoxylin and Eosin; original magnification 40X).

hypothyroidism unlikely (Scott-Moncrieff and Nelson, 1998). In humans, a reduced TSH response is expected in secondary and a normal or exaggerated response in tertiary hypothyroidism. Less commonly, absent and impaired responses have been recorded with hypothalamic disease, with only occasional patients with pituitary disease exhibiting a normal response (Martino and Pinchero, 2005). Therefore, these results are highly suggestive of tertiary hypothyroidism.

In humans, endogenous TRH can be assayed to attempt to differentiate secondary and tertiary hypothyroidism but, as most TRH in peripheral blood originates from extrahypothalamic sources, it cannot be reliably used to differentiate between the two conditions (Engler et al., 1981; Martino and Pinchero, 2005). In addition, this assay has not been validated in the dog.

In this case, a diagnosis of tertiary hypothyroidism was further supported by the destruction of hypothalamic tissue by the expanding pituitary mass, as evident on both MRI and post mortem examination. In theory, any expansive or infiltrative mass could affect hypothalamic TRH or pituitary TSH producing cells. It is likely in this case that the infiltrative adenoma was a functional pituitary macrotumour, responsible for the pituitary dependent hyperadrenocorticism earlier diagnosed.
Other endocrinopathies were not detected, but hyposecretion of TSH as the sole demonstrable abnormality has been reported in humans in both acquired and congenital forms of secondary hypothyroidism, and similar monotropic deficiencies are theoretically possible within the hypothalamus (Larsen and Davies, 2003). Concurrent pituitary hormone deficiencies cannot be fully excluded because specific tests for other pituitary hormones were not performed but the lack of supportive clinical signs makes such deficiencies unlikely.

The presence of the atrophic changes within the thyroid glands is consistent with levothyroxine administration. Similar changes are expected with central hypothyroidism, but biopsy prior to levothyroxine therapy would have been necessary to confirm this diagnosis. Such an invasive procedure was not considered justified. However, there was no evidence of either lymphocytic thyroiditis or idiopathic thyroidal atrophy, thereby making primary hypothyroidism unlikely.

In this case, progressive expansion and effacement of the overlying hypothalamus lead to the development of tertiary hypothyroidism, with sparing of TSH-producing cells within the pituitary gland, as demonstrated by TRH stimulation test results. This case report confirms that tertiary hypothyroidism exists in dogs, albeit rarely. 


\section{References}

Barr, S.C. (1985). Pituitary tumour causing multiple endocrinopathies in a dog. Australian Veterinary Journal 62: 127-129.

Brabant, A., Brabant, G., Schuermeyer, T., Ranft, U., Schmidt, F.W., Hesch, R.D. and von zur Muhlen, A. (1989). The role of glucocorticoids in the regulation of thyrotropin. Acta Endocrinologica 121: 95-100. Dillon, A.R., Spano, J.S. and Powers, R.D. (1980). Prednisolone induced hematological, biochemical, and histological changes in the dog. Journal of the American Animal Hospital Association 16: 831-837.

Dixon, R.M. (2004). Canine hypothyroidism. In: Manual of Canine and Feline Endocrinology. $3^{\text {rd }}$ edn.. Edited by C.T. Mooney and M.E. Peterson. BSAVA Publications, Quedgeley, UK. pp76-94.

Dixon, R.M. and Mooney, C.T. (1999). Evaluation of serum free thyroxine and thyrotropin concentrations in the diagnosis of canine hypothyroidism. Journal of Small Animal Practice 40: 72-78.

Dixon, R.M., Reid, S.W.J. and Mooney, C.T. (1999). Epidemiological, clinical, haematological and biochemical characteristics of canine hypothyroidism. Veterinary Record 145: 481-487.

Dixon, R.M., Reid, S.W.J. and Mooney, C.T. (2002). Treatment and therapeutic monitoring of canine hypothyroidism. Journal of Small Animal Practice 43: 334-340.

Eigenmann, J.E. (1981). Diagnosis and treatment of dwarfism in a German Shepherd dog. Journal of the American Animal Hospital Association 17: 798-804

Engler, D., Scanlon, M.F. and Jackson, I.M. (1981). Thyrotropin-releasing hormone in the systemic circulation of the neonatal rat is derived from the pancreas and other extraneural tissues. Journal of Clinical Investigation 67: 800-808.

Feldman, E.C. and Nelson, R.W. (1987). Hypothyroidism. In: Canine and Feline Endocrinology and Reproduction. $1^{\text {st }}$ edn. Edited by E.C. Feldman and R.W. Nelson. Philadelphia: W.B. Saunders. pp55-90.

Feldman, E.C. and Nelson, R.W. (2004). Canine hypothyroidism. In: Canine and Feline Endocrinology and Reproduction. $3^{\text {td }}$ edn. Edited by E.C. Feldman and R.W. Nelson. Missouri: W.B. Saunders pp88-152.

Ferguson, D.C. and Peterson, M.E. (1992). Serum free and total iodothyronine concentrations in dogs with hyperadrenocorticism. American Journal of Veterinary Research 53: 1636-1640.

Greco, D.S., Feldman, E.C., Peterson, M.E., Turner, J.L., Hodges, C.M. and Shipman, L.W. (1991). Congenital hypothyroid dwarfism in a family of giant schnauzers. Journal of Veterinary Internal Medicine 5: 57-65.

Hamann, F. , Kooistra, H. S., Mol, J. A. , Gottschalk, S. , Bartels, T. and Runberk, A. (1999). Pituitary function and morphology in two German Shepherd dogs with congenital dwarfism. Veterinary Record 144: 644-646. Hare, W.R. (1993). Primary suprasellar germ cell tumor in a dog. Journal of the American Veterinary Medical Association 203: 1432-1433.

Kantrowitz, L.B., Peterson, M.E., Melian, C. and Nichols, R. (2001).

Serum total thyroxine, total triiodothyronine, free thyroxine, and thyrotropin concentrations in dogs with nonthyroidal disease. Journal of the American Veterinary Medical Association 219: 765-769.

Kooistra, H.S., Voorhout, G. Mol, J.A, and Rijnberk, A. (2000). Combined pituitary hormone deficiency in German shepherd dogs with dwarfism. Domestic Animal Endocrinology 19: 177-190.

Larsen, P.R. and Davies, T.F. (2003). Hypothyroidism and thyroiditis. In: Williams Textbook of Endocrinology. $10^{\text {th }}$ edn. Edited by P.R. Larsen, H.M. Kronenberg, S. Melmed and K.S Polonsky. Philadelphia: Saunders pp423455.

Martino, E. and Pinchero, A. (2005). Central hypothyroidism. In: Werner and Ingbar's The Thyroid, A Fundamental and Clinical Text. $9^{\text {th }}$ edn. Edited by L.E. Braverman and R.D. Utiger. Philadelphia: Lippincott, Williams and Wilkins pp754-768.

Mellanby, R.J., Jeffery, N.D., Gopal, M.S. and Herrtage, M.E. (2005).

Secondary hypothyroidism following head trauma in a cat. Journal of

Feline Medicine and Surgery 7: 135-139.
Mooney, C.T. and Anderson, T.J. (1993). Congenital hypothyroidism in a boxer dog. Journal of Small Animal Practice 34: 31-35.

Moore, G.E., Ferguson, D.C. and Hoenig, M. (1993). Effects of oral administration of anti-inflammatory doses of prednisone on thyroid hormone response to thyrotropin-releasing hormone and thyrotropin in clinically normal dogs. American Journal of Veterinary Research 54: 130-135. Neer, T.M. and Reavis, D.U. (1983). Craniopharyngioma and associated central diabetes insipidus and hypothyroidism in a dog. Journal of the American Veterinary Medical Association 182: 519-520.

Nelson, R.W., Ihle, S.L., Feldman, E.C. and Bottoms, G.D. (1991). Serum free thyroxine concentration in healthy dogs, dogs with hypothyroidism, and euthyroid dogs with concurrent illness. Journal of the American Veterinary Medical Association 198: 1401-1407.

Panciera, D.L. (1998). Canine hypothyroidism. In: Manual of Small Animal Endocrinology. $2^{\text {nd }}$ edn. Edited by A.G. Torrance and C.T. Mooney. Cheltenham: British Small Animal Veterinary Association. pp 103-113 Panciera, D.L. (1994). Hypothyroidism in dogs: 66 cases (1987-1992). Journal of the American Veterinary Medical Association 204: 761-767. Peterson, M.E., Ferguson, D.E., Kintzer, P.P. and Drucker, W.D. (1984). Effects of spontaneous hyperadrenocorticism on serum thyroid hormone concentrations in the dog. American Journal of Veterinary Research 45: 20342038.

Roover, K. De, Daminet, S., Duchateau, L. and Carmichael, N. (2003). Effect of storage of recombinant human thyrotropin on thyroidstimulating hormone response testing in euthyroid dogs. Proceedings of the European College of Veterinary Internal Medicine: Companion Animals Congress p148.

Sauvé, F. and Paradis, M. (2000). Use of recombinant human thyroidstimulating hormone for thyrotropin stimulation test in euthyroid dogs. Canadian Veterinary Journal 41: 215-219.

Scott-Moncrieff, J.C. and Nelson, R.W. (1998). Changes in serum thyroid stimulating hormone concentration in response to administration of thyrotropin-releasing hormone to healthy dogs, hypothyroid dogs and euthyroid dogs with concurrent disease. Journal of the American Veterinary Medical Association 213: 1435-1438.

Torres, S., McKeever, P.J. and Johnston, S.D. (1991). Effects of oral administration of prednisolone on thyroid function in dogs. American Journal of Veterinary Research 52: 416-421. 